\title{
ESTUDIO DE FACTORES QUE PROMUEVEN EL ÉXITO EN MIPYMES DEL CANTÓN GUARANDA, PROVINCIA DE BOLIIVAR
}

\section{STUDY OF FACTORS THAT PROMOTE THE SUCCESS IN MIPYMES OF THE CANTON GUARANDA, COUNTY BOLIVAR}

Aída Isabel Jaya Escobar, Ph. D. Doctora en Ciencias Económicas (Cuba). Docente de Universidad Estatal de Bolívar, Ecuador. jayaisabel@yahoo.es

Karina Johanna Iza López, Mgs. Magíster en Auditoría Integral (Ecuador). Docente de la Universidad Estatal de Bolívar, Ecuador. kari.iza@hotmail.com

Olga Angélica Gavilema Vistín, Mgs. Magíster en Gerencia Empresarial (Ecuador). Docente de la Universidad Estatal de Bolívar, Ecuador. olgagavilema@yahoo.es

\section{ARTÍCULO DE INVESTIGACIÓN}

Recibido: 5 de septiembre de 2018.

Aceptado: 31 de octubre de 2018.

\section{RESUMEN}

A nivel global es de gran interés para los propietarios y/o administradores de las Medianas y pequeñas empresas (Mipymes) conocer sobre los factores que les permita mejorar su gestión y por ende alcanzar el éxito en su quehacer empresarial. En tal sentido el objetivo de la presente investigación es analizar los factores que influyen en el éxito de una micro, pequeña y mediana empresas formales del cantón Guaranda, provincia Bolívar, en aras de coadyuvar a minimizar los altos niveles de extinción o desaparición en el mercado. La investigación enmarca un enfoque metodológico cuali-cuantitativo, con un diseño, tipo y nivel de la investigación no experimental, descriptiva y documental en ese orden. La población considerada fue de 969 Mipymes ubicadas en las 11 parroquias urbanas y rurales del cantón 
Guaranda, para la recolección de la información se hizo uso de técnicas como las encuestas y las entrevistas que fueron aplicadas a una muestra de 554 mipymes de las parroquias objeto de estudio. La investigación permitió conocer los principales factores que promueven el éxito en los negocios de este sector son el conocimiento del mercado, capacidad de financiamiento, conocimiento de estrategias de publicidad y propaganda, ostentar un producto o servicio adecuado, conocimiento de estrategias de comercialización, capacidad de enfrentar la competencia, planificación adecuada, entre otros.

Palabras clave: emprendimiento, mipymes, factores de éxito, sostenibilidad empresarial.

\section{ABSTRACT}

At global level it is of great interest for the owners administrating and manage of the Mipymes to know about the factors that it allows them to improve their administration and for ende to reach the success in its managerial chore. In such a sense the objective of the present investigation is to analyze the factors that influence in the success of a micro, small and medium formal companies of Guaranda canton, Bolivar province, for the sake of cooperating to minimize the high levels of extinction or disappearance in the market. The investigation frames a cuali-quantitative methodological focus, with a design, type and level of the researching not experimental, descriptive and documental in that order. The considered population was of 969 Mipymes located in the 11 urban and rural parishes of Guaranda canton, for the gathering of the information it uses was made of technical as the survey and the interviews that they were applied to a sample of 554 mipymes of the parishes study object. The investigation allowed to know the main factors that promote the success in the business of this sector they are the knowledge of the market, financing capacity, knowledge of strategies of publicity and propaganda, to show a product or appropriate service, knowledge strategies of the commercialization, capacity to face the competition, appropriate planning, among others.

Keywords: entrepreneurship, mipymes, success factors, business sustainability.

\section{INTRODUCCIÓN}

En la actualidad las micro, pequeñas y medianas empresas, se constituyen en un pilar fundamental de la economía de un país, porque son generadoras de riqueza avizorados en cuanto a la producción y el empleo (Cravo, Bettina, \& Gourlay, 2014). Enunciado que concuerda con los autores (Estrada, García y Sánchez, 2009), que señalan que las micro, 
pequeñas y medianas empresas, tienen una gran importancia socioeconómica y territorial, por la generación de riqueza y empleos en el horizonte regional, nacional y mundial. Las micro, pequeña y medianas empresas en gran medida se ven afectadas por aspectos asociados a la globalización de los mercados en los cuales maniobran y por los constantes cambios en los entornos de tipo general y específico, lo que pone en riesgo su supervivencia (Ahmedova, 2015). En éste contexto los gobiernos de los países del mundo aceptan y reconocen la importancia de éstas organizaciones como principal fuente de desarrollo y progreso económico, por tal razón crean y aprueban políticas económicas que favorezca su quehacer; así como también establecen entidades encargadas de regularlas con preceptos jurídicos apropiados para una mejor administración (Gill, Nahum, \& Vivek, 2011).

El surgimiento de las mipymes está dado básicamente por la necesidad económica o desarrollo profesional del emprendedor que las encausa a ser un motor del desarrollo económico y social regional, nacional y mundial, organizaciones que hoy por hoy se han convertido en una oportunidad válida para la mejora de la calidad de vida de los habitantes del territorio donde operan. En éste marco a una mipyme se la concibe como un conjunto de organizaciones que son segmentadas en micro, pequeña y medianas empresas, por elementos como el volumen de ventas, número de trabajadores, millones en activos, entre otros (SRI, 2012).

Apartado que concuerda con el INEC (2010), señala que las mipymes en el Ecuador tienen varios factores que se han considerado para determinarlas como tal, como son el número de trabajadores, monto y capacidad de producción, volumen de ventas, capital que posee la empresa, administración independiente, la mayor parte son empresas familiares que se constituyen como compañía limitada y también las opera como persona natural. En cuanto a los empleados las microempresas albergan hasta 9 empleados, las pequeñas empresas hasta 49 empleados, mientras que las medianas hasta 99 y las grandes empresas de 100 en adelante.

Las mipymes en el Ecuador han evolucionado porque tienen un gran potencial en la generación de ingresos como resultado del grado de producción y empleo y uno de los más importantes aportes en el crecimiento económico del país. El desempeño de las mipymes es producto del ajuste de sus procesos a las necesidades del mercado, sin embargo, existen muchas dificultades que las atañen relacionadas a la falta de conocimiento en el ámbito empresarial que se refleja en la poca o nula especialización en la administración de las mismas, en esencia la dirección se encuentra a cargo de una sola persona, la cual cuenta con 
muy pocos conocimientos y como consecuencia los resultados no son tan halagadores, falta capital y liquidez, esta última por ausencia de mecanismos de apoyo y asesoramiento para el financiamiento, poca disponibilidad de maquinaria y herramientas tecnológicas que le permitan mejorar su producción y brindar un servicio de calidad que satisfaga al cliente.

Las debilidades de las mipymes se instituyen en factores que podría afectar la continuidad de su quehacer en el mercado. Asimismo, ha sido considerado como factor limitante en su trabajo, que la fuente principal de fondeo de la mipyme se adscribe en relación a que la persona que aporta el capital es la misma que la administra, confundiéndose la fuente de financiamiento de la empresa y la familia; también por ser una empresa familiar no se exige la profesionalización de quien la dirige y peor aún la mejora de los procesos empresariales. Además, que los propietarios de estas organizaciones desconocen cuáles son las IFI'S que ofrecen fuentes de financiamiento formales y la manera en que estas operan en cuanto a requisitos y garantías, lo cual está dado por la falta de conocimiento de herramientas que le permitan exponer la situación financiera de su negocio.

El cantón Guaranda se caracteriza por el desarrollo empresarial, lo que ha permitido a su población mejorar su calidad de vida. La economía del cantón se ha fortalecido por el emprendimiento, encauzando a la participación de las mipymes en el mercado con productos y/o servicios diversos y al trabajo en un ambiente en el que predominen los principios de igualdad y ayuda mutua, bajo el marco del valor del respeto, logrando así empleo digno para todos. Las mipymes del Cantón Guaranda son actualmente motores de su economía, ya que el desarrollo de las mismas es muy alto, pero por otro lado como ya se indicó existen algunos factores que de alguna manera inhiben su desarrollo, limitación que se ven reflejados en resultados adversos por pocos ingresos en sus ventas y en casos más severos el cierre de los negocios, ya que la economía que se atraviesa en el mercado no están acorde a las exigencias que vivimos en la actualidad.

Es por lo expuesto que el objetivo de esta investigación es estudiar los factores que promueven el éxito de las mipymes en las 11 parroquias urbanas y rurales del cantón Guaranda para coadyuvar en la administración de las micro, pequeñas y medianas empresas.

\section{REVISIÓN TEÓRICA}

Lo más importante de un emprendimiento es la persona que crea el negocio como lo es el emprendedor, catalogado como el creador de su propio andar empresarial, lo que le diferencia 
del empresario de empresas grandes es el deseo de ser el gestor de su propio destino, sin dejar de lado la preocupación por los demás, en el sentido que los índices elevados de la falta de empleo y el subempleo se convierte en una problemática social, siempre enmarcando su accionar en sus principios. El término emprendedor es aquella persona que busca de manera constante una oportunidad para crear valor en la sociedad, sea por medio de la creación de un negocio o la mejora de un negocio existente, asumiendo riesgos como contrapartida a generar buenos resultados, como producto de sus esfuerzos (Longenecker, 2012).

Las mipymes en la actualidad se han constituido en el centro de atención de diversos ámbitos como el empresarial, academia y profesional; puesto que hoy por hoy, es reconocido como una coyuntura de progreso por ser la alternativa real para el desarrollo a nivel latinoamericano y mundial (Hernández, 2007). Desde el punto de vista cognitivo, las mipymes son agrupaciones que integran un campo de estudio para la construcción conceptual desde tres ámbitos: 1) las alineaciones que se apiñan en dar paso a la adaptabilidad Ej. TIC's, la flexibilidad en la habilidad de especialización que se vislumbra en la mejora de procesos de producción, 2) las que incursionan en el aprendizaje de la eficiente asignación de los recursos de producción en el contexto de los requerimientos y necesidades externos del conocimiento y sobre la información de su estructura para un apropiado desempeño en los mercados; y, 3) las que centran su atención en el cumplimiento de los preceptos jurídicos y los costos de producción de bienes y/o servicios (Vega, et al. 2011).

Por ende, las mipymes contribuyen a mejorar la problemática social en relación a mejorar la cantidad de ingresos de la población, al crear un puente entre la necesidad y la satisfacción del consumidor, porque una mipyme es producto de materializar una idea empresarial en diligencias entorno a la producción, comercial, y de servicios en pequeña escala. En este contexto las mipymes son mecanismo de captación y utilización de ahorros a una escala menor, para hacerlos fructíferos (Rodríguez, 2006).

En el desarrollo de las mipymes se ha vislumbrado factores que inhiben su crecimiento y su aporte con la comunidad que deben ser atenuados mediante estrategias que permitan transformar a estos limitantes en factores que promuevan el éxito de las mismas. Porque hay que entender las mipymes fortalecidas aportan a equilibrar su crecimiento alineado al progreso y estabilidad social por la generación de fuentes de empleo y por consiguiente asiste a la economía de un país (Ramírez y Venegas, 2008). Históricamente, los factores de éxito empresarial han sido concebidos y definidos desde varias ópticas, siendo análoga al 
establecimiento e implementación de buenas estrategias y de la planificación institucional (Vásquez, 2002).

Estos factores deben ser tomados como elementos que conducen al éxito siempre que vaya alineado a las necesidades reales de la empresa y tomando en cuenta la competencia latente y las condiciones en el mercado; puesto que la micro, pequeña y mediana empresa puede incurrir en desperdicios innecesarios de recursos cuando no se optimizan por la falta de un análisis minucioso y una adecuada planificación (Pulido, 2010).

La necesidad de conocer los factores de éxito empresarial ha dado lugar a la atención de empresarios, en cuanto a los beneficios que estos propician para sus organizaciones en el éxito de la administración, talento humano y volúmenes de producción y ventas (Gutiérrez, 2009).

En la gestión empresarial se hace necesario manifestar que deben estar latentes factores que promuevan su éxito, tal es el caso de conocimiento del mercado en el que opera, una apropiada cultura y clima organizacional mediante la capacidad de resolución de conflictos, apropiado manejo de recursos resultado de fuentes financiamiento internas o externas, adecuados canales de comunicación, entre otras. Además, que la posibilidad de supervivencia en el mercado radica en extraer beneficios de factores para mantenerse posicionadas en la mente de los consumidores como mipymes exitosas en el entorno social y económico regional, nacional o internacional manteniéndose en el tiempo propiciando una eficiente producción y siendo competitivas en el medio (López, 2009).

Los factores de éxitos son los recursos, habilidades, destrezas, conocimiento y particularidades de las organizaciones que fomenta la supervivencia y permanencia en el mercado a través del tiempo, mediante el cumplimiento de sus propósitos institucionales (Lynch, 2003). Por otro lado, los factores críticos de éxito, según Scali y Tapia (2012) son los acontecimientos y elementos sean endógenos o exógenos que tienen una alta probabilidad de darse que deben ser manejados en pos de mejorar el quehacer empresarial de las organizaciones. Al ser catalogados como factores críticos de éxito hacen referencia a lo que es fundamental para caracterizarla como exitosa por su buen desempeño en el mercado y de no cumplirse estos factores podrían afectar a la generación de ingresos y de competitividad del negocio, en si generan valores adversos, frente a empresas que si las incluyen en su administración. 
A los factores de éxito también se les define como indicadores que deben ser analizados por los empresarios antes de la creación y lanzamiento del bien o un servicio en el mercado, puesto que determinan el éxito o el fracaso de las empresas, para ser claros son catalogados como factores de éxito cuando se enfocan en la innovación, es decir al cambio planificado y cuando inciden en la identificación de oportunidades en el mercado para una acertada toma de decisiones y a generar el compromiso del recurso humano. De este modo, los factores de éxito deben ser utilizados para que las mipymes alcancen el éxito planeado crear, aumentar o mantener su posición en el mercado, pero esto sin dejar de lado un análisis micro y macro, en éste último del entorno geográfico, económico, político y social (Castro y Rufino, 2015).

Por lo expuesto Martín (2013), indica que para definir los factores críticos de éxito de los negocios debe entenderse y diferenciarse dos términos claves: 1) los factores claves de éxito que son las bondades de los productos y/o servicios que produce y oferta una mipyme, para satisfacer la oportunidad avizorada en el mercado que se traduce en saciar las necesidades del consumidor mediante la exposición de su producción mediante estrategias de publicidad y promoción. Concibiendo que las peculiaridades de los productos y/o servicios se constituyen en la calidad que se centra en la presentación, la garantía, precio, canales de distribución, entre otros. 2) Factores generadores del éxito se refieren a la capacidad de la empresa en lo técnico, económico, financiero, administrativo, entre otros para producir, diseñar y dar a conocer el producto y/o servicio mediante estrategias de mercadeo, esto para hacer de la empresa competitiva en un mercado cada vez más agresivo. Por ende, los dos factores están íntimamente relacionados y orientados a ayudar a la empresa a satisfacer a sus clientes.

\section{MATERIALES Y MÉTODOS}

Para cumplir con el propósito de la investigación como es estudiar los factores de éxito que promueven el éxito de las mipymes, se utilizó un enfoque metodológico cuali-cuantitativo, con un diseño, tipo y nivel de la investigación no experimental, descriptiva y documental en ese orden. La población considerada fue de 969 mipymes ubicadas en las 11 parroquias urbanas y rurales del cantón Guaranda como son: parroquias urbanas Veintimilla, Chávez y Guanujo y las parroquias rurales Facundo Vela, Julio Moreno, Salinas, San Lorenzo, San Luis de Pambil, San Simón, Santa Fe y Simiatug, a partir de este número, se calculó una muestra no probabilística de 554 mipymes, resultado que fue producto de tener presente un nivel de confianza del $95 \%$ como un margen de error \pm 5 . La muestra determinada fue resultado de estratificar la población por parroquia, quedando la muestra la cual se presenta a continuación: 
Tabla 1. Parroquias Urbanas y Rurales del cantón Guaranda.

\begin{tabular}{lr}
\hline SIMIATUG & 43 \\
\hline JULIO MORENO & 3 \\
SAN SIMÓN & 8 \\
SALINAS & 52 \\
FACUNDO VELA & 14 \\
SAN LORENZO & 12 \\
SAN LUIS DE PAMBIL & 58 \\
SANTA FÉ & 5 \\
GUANUJO & 64 \\
CHÁVEZ & 130 \\
VEINTIMILLA & 165 \\
TOTAL & 554 \\
\hline
\end{tabular}

Fuente: elaboración propia.

Las técnicas empleadas para la recolección de información fueron las encuestas y entrevistas, posterior a la estructura de un cuestionario y guía temática, documentos instituidos por interrogantes inscritas a determinar las principales características y los factores de éxito de las mipymes. Las encuestas fueron aplicadas a propietarios y/o administradores de las micro, pequeñas y medianas empresas, que son los principales actores versados en aspectos asociados a éstas organizaciones. Adicionalmente para reunir información asociada a la temática objeto de análisis se hizo una revisión documental actualizada en libros, revistas, reportajes y demás documentos asociados a la temática objeto de estudio.

\section{ANÁLISIS DE RESULTADOS}

Una vez aplicadas las encuestas y entrevistas a los propietarios y/o administradores de los negocios ubicados en las 11 parroquias urbanas y rurales del cantón Guaranda, situado en la zona 5 del país, se analizaron los resultados de cada pregunta del cuestionario de las técnicas de recolección de información, que permitieron establecer las tipologías y elementos más particulares que representan el inicio y permanencia de las mipymes en el mercado; así como también los factores que promueven el éxito en su accionar. 


\subsection{Características de las MIPYMES.}

La variedad de género en las empresas ajenas al giro de su negocio, es un elemento importante en él éxito de estás por la incorporación de ideas que generan una ventaja de competencia en el mercado. Los negocios ubicados en las 11 parroquias urbanas y rurales del cantón Guaranda son administrados en un $57 \%$ por mujeres y el $43 \%$ restante por hombres. Por otro lado, la actual situación conyuntural empresarial del país ha generado la necesidad de estudio de la edad como elemento prioritario en la gestión de las mipymes. La edad que exhiben los propietarios y/o administradores de éstas que son de género masculino, está en el orden que sigue, el 38,33\% de $20-30$ años, $27,50 \%$ de $31-40$ años, $15,42 \%$ de 41 50 años, el 10,42\% de 51-60 años, el 7,50\% más de 60 años y apenas el 0,83\% denotan una edad de menor a 20 años, tal es así que el $66 \%$ presentan una edad entre 20 a 40 años. En cambio, las personas valoradas de género femenino, revelan una edad que bordean los siguientes rangos; así, el 39,81\% de 20-30 años, el 24,52\% de 31-40 años, el 15,92\% de 41 50 años, el 8,92\% entre los rangos 51-60 años y más de 60 años; y apenas el 1,91\% de Menor a 20 años. El $66 \%$ y el $65 \%$ de hombres y mujeres que gestionan sus negocios, en este orden tiene una edad que va en el rango de 20 a 40 años, lo que facilita interpretar que la administración de una mipyme es realizada por personas que tiene una edad suficiente en la que muestre la madurez necesaria de adquirir, desarrollar y aplicar las sapiencias asociadas al proceso de administración.

Los estudios académicos realizados por los propietarios y/o administradores de las miymes se ven reflejadas en el orden de participación; así, el 54,15\% de los encuestados muestran un grado de formación de tipo secundaria, el 20,94\% primaria, el 20,40\% pregrado, el 3,07\% no contesta a la interrogante y apenas el 1,44\% de posgrado. En gran medida la formación formal oscila en un $75 \%$ en los niveles de primaria y secundaria y apena el $25 \%$ en los niveles más elevados de estudios. Esta variable va de la mano con la formación empresarial. En este sentido más de la mitad de las mipymes son administradas por personas que no tiene una formación en el manejo de negocios, específicamente el 59,21\% y el 39,35\% restante si cuenta con una formación que viabiliza la generación de estrategias que permitan la supervivencia en el mercado de sus negocios y el 1,44\% no contesta a la interrogante.

En anuencia al tamaño de la mipyme, el $50 \%$ indican que es pequeña, el $32 \%$ micro, $14 \%$ mediana y el $4 \%$ no respondieron a la interrogante. Las mipymes en el cantón Guaranda en gran medida desarrollan tareas económicas de tipo comercial, el $74 \%$, servicios administrativos y de apoyo, el $7 \%$, alojamiento y comidas, el $4 \%$, profesionales, científicos y 
técnicos el 3\%, el $2 \%$ dejaron en blanco, manufacturas, construcción y otro tipo de actividades, el $2 \%$ y de agricultura y ganadería, Transporte y almacenamiento, el $1 \%$.

En cuanto al sector al que pertenece las mipymes, se determinó que el $69 \%$ despliegan diligencias de tipo comercial, el $26 \%$ de los negocios pertenecen al sector servicios, el $2 \%$ pertenece al sector industrial y el $3 \%$ de los encuestados dejan en blanco la interrogante.

\subsection{Establecimiento de las mipymes.}

Los propietarios y/o administradores de las mipymes están totalmente de acuerdo que una de las razones que les motivaron a iniciar su negocio fue para tener trabajo, en este aspecto están totalmente de acuerdo el $62 \%$, están de acuerdo el $19 \%$, esto básicamente frente a los elevados índices de desempleo y subempleo, se mostraron indecisos el $2 \%$, están en desacuerdo el $3 \%$ y finalmente el $14 \%$ restante indicaron estar en total desacuerdo.

Al hablar de las razones que impulsó al emprendedor iniciar un negocio, se encuentran: 1) para tener trabajo y para su familia, el 61,65\% está totalmente de acuerdo, el 18,95\% está de acuerdo, el 2,35\% se mostraron indecisos, el 3,07\% están en desacuerdo, el 13,90\% están en totalmente desacuerdo y el $0,18 \%$ dejaron en blanco la interrogante. 2) no les gusta depender de jefes, es así que están totalmente de acuerdo el 44, 22\%, el 30, 14\% están de acuerdo, el 7,22\% se mostraron indecisos, el 2,71\% están en desacuerdo, el 15,52\% indicaron estar en total desacuerdo y el $0,18 \%$ dejaron en blanco a la interrogante. 3) siempre le gustó tener negocios, es así que el 55,05\% están totalmente de acuerdo, el 21,12\% están de acuerdo, el $5,42 \%$ se mostraron indecisos, el 3,61\% están en desacuerdo y el $14,62 \%$ indicaron estar en total desacuerdo.4) no disponía de tiempo para sujetarse a un horario de trabajo el $47,65 \%$ está totalmente de acuerdo, el 18,95\% están de acuerdo, el $12,27 \%$ se mostraron indecisos, el 5,23\% están en desacuerdo, el 15,70\% indicaron estar en total desacuerdo y el $0,18 \%$ dejaron en blanco la interrogante. 4) piensa que se gana más en un negocio que como empleado, el 50,18\% está totalmente de acuerdo, el 19,68\% está de acuerdo, los 7,58\% indecisos, el 5,05\% en desacuerdo, el $17,33 \%$ en total desacuerdo y el $0,18 \%$ dejaron en blanco la interrogante. 6 ) otras razones, el $14,98 \%$ de los encuestados están totalmente de acuerdo, el $82,31 \%$ indicaron estar en total desacuerdo, en cambio el $2,71 \%$ no dieron respuesta a esta interrogante.

Es indispensable también hacer hincapié que el $64 \%$ de los encuestados señalaron que, para iniciar su negocio de acuerdo a su experiencia, los trámites para hacerlo son demasiado 
extensos y complicados, el 33\% señalan que no lo es y el 3\% no responden y dejan en blanco la interrogante. Para ser específicos en cuanto al grado de complicación de los trámites previos a iniciar un negocio se consultó sobre las instituciones que se ven inmersas en los mismos, tal es el caso: 1) Municipio el 30,69\% está totalmente de acuerdo, el 15,34\% está de acuerdo, el 14,98\% está indeciso, el 19,49\% está en desacuerdo, el 18,95\% evidencia estar totalmente en desacuerdo y el 0,54\% dejó en blanco. 2) Bomberos el 40,79\% está totalmente de acuerdo, el 17,69\% está de acuerdo, el 14,62\% está indeciso, el 11,73\% está en desacuerdo, 14,62\% totalmente en desacuerdo y el 0,54\% dejó en blanco. 3) Dirección de Salud el 50,72\% está totalmente de acuerdo, el 13,54\% está de acuerdo, el 7,58\% está indeciso, el 9,75\% está en desacuerdo, $17,51 \%$ totalmente en desacuerdo y el 0,54\% dejó en blanco. 4) MAGAP el $57,22 \%$ está totalmente de acuerdo, el 9,93\% está de acuerdo, el 7,22\% está indeciso, el 5,96\% está en desacuerdo, 18,59\% totalmente en desacuerdo y el 1,08\% dejó en blanco.5) Dirección de Turismo el 58,48\% está totalmente de acuerdo, el 7,22\% está de acuerdo, el 6,50\% está indeciso, el 6,50\% está en desacuerdo, 20,22\% totalmente en desacuerdo y el 1,08\% dejó en blanco. 6) Gobernación el 53,79\% está totalmente de acuerdo, el 5,78\% está de acuerdo, el 15,70\% está indeciso, el 8,66\% está en desacuerdo, 12,64\% totalmente en desacuerdo y el 3,43\% dejó en blanco. 7) SRI el 41,88\% está totalmente de acuerdo, el 15,52\% está de acuerdo, el 11,91\% está indeciso, el 16,43\% está en desacuerdo, $13,72 \%$ totalmente en desacuerdo y el $0,54 \%$ dejó en blanco. 7 ) además, fue menester indagar sobre la complejidad de los trámites en otras instituciones de notando que el $11,37 \%$, $88,09 \%$ está totalmente en desacuerdo y el $0,54 \%$ dejó en blanco.

\subsection{Permanencia en el mercado.}

Existen muchas estrategias que pueden asegurar la permanencia de los negocios en el mercado del presente y futuro. La permanencia de los negocios en el mercado se muestra según el grado de participación el $76 \%$ mayor a 1 año, el $9 \%$ menor o igual a 1 año, el $6 \%$ menor o igual a seis meses y mayor a 6 meses y el $3 \%$ deja en blanco.

El sacar adelante a una mipyme no es fácil puesto que influyen en el éxito de su quehacer factores externos, entre uno de ellos las políticas económicas emitidas por el Gobierno Nacional. Es así que el $67 \%$ mencionan que éstas influyen, el $30 \%$ que no y el $3 \%$ restante dejaron en blanco.

En el mercado que es cada vez más agresivo las empresas asociado a su capacidad económica que es un factor que delimita su tamaño, están expuestos a riesgos inherentes a: 
1) Personas, Procesos, Tecnología de la Información y Eventos Externos, en éste sentido el $41,70 \%$ está totalmente de acuerdo, el 27,80\% está de acuerdo, el 12,64\% está indeciso, el $7,58 \%$ está en desacuerdo, $7,04 \%$ totalmente en desacuerdo y el 3,25\% dejó en blanco. 2) Falta de Fuentes de financiamiento, el 37,36\% está totalmente de acuerdo, el 30,69\% está de acuerdo, el $11,37 \%$ está indeciso, el 5,78\% está en desacuerdo, 12,09\% totalmente en desacuerdo y el 2,71\% dejó en blanco. 3) Los cambios en las variables de mercado, como tasas de interés, también es considerado como un riesgo, en este contexto el 35,20\% está totalmente de acuerdo, el 28,34\% está de acuerdo, el 13,90\% está indeciso, el 6,68\% está en desacuerdo, 13,72\% totalmente en desacuerdo y el 2,17\% dejó en blanco. 4) Así mismo, un riesgo al que están expuestas las mipymes es la poca capacidad de hacer frente deudas contraídas que se traduce en el riesgo de liquidez, en éste contexto el $28,88 \%$ está totalmente de acuerdo, el $26,17 \%$ está de acuerdo, el 16,25\% está indeciso, el 9,39\% está en desacuerdo, $18,41 \%$ totalmente en desacuerdo y el 0,90\% dejó en blanco. Por otro lado, en relación a que no existen riesgos el $11,19 \%$ está totalmente de acuerdo, el $0,36 \%$ está de acuerdo, el 0,72\% está indeciso, el 0,36\% está en desacuerdo, 79,96\% totalmente en desacuerdo y el 7,40\% dejó en blanco. En este apartado es necesario dejar constancia que el riesgo cero no existe en cualquier tarea empresarial o de otro tipo el riesgo está latente.

En cuanto al asesoramiento recibido anterior al establecimiento de la mipyme el $72 \%$ de los propietarios y/o administradores señalan que no han recibido un acompañamiento, el $24 \%$ restante señalan que y el $3 \%$ dejaron en blanco la interrogante. Entendiendo que el asesoramiento consiste en suministrar la información suficiente y competente al emprendedor para la acertada toma de decisiones anterior a la creación de un negocio.

También se valoró sobre los resultados alcanzados durante un periodo económico, que se ven reflejados en pérdidas y ganancias el $53 \%$ indican que los resultados han sido buenos, el $25 \%$ regulares, $11 \%$ muy buenos, $6 \%$ malos, 2 muy malos y el $3 \%$ dejaron en blanco. Tal es así, que el $33 \%$ de los encuestados expresan que los resultados no son tan halagadores.

Un elemento básico de análisis en los negocios es también la calidad del producto, aspecto que se ve en la percepción del cliente en cuanto a su satisfacción. El 95\% de los propietarios y/administradores de las mipymes señalan que los productos ofrecidos por su negocio en el mercado son de calidad, el $7 \%$ son más reales y mencionan que no y el $3 \%$ no contestaron la interrogante. 
En inherencia a la calificación de su formación empresarial en el momento de emprender y gestionar su negocio, el $62 \%$ mencionan que es buena, $19 \%$ muy buena, $13 \%$ regular, $1 \%$ mala y muy mala y el $3 \%$ dejaron en blanco. Aunque, el $81 \%$ de los propietarios y/o administradores muestran que su formación empresarial es buena y muy buena, se le hizo una valoración sobre la formación empresarial en diversos aspectos como: 1) estudio de mercado, el $61,01 \%$ está totalmente de acuerdo, el $24,91 \%$ está de acuerdo, el $6,14 \%$ está indeciso, el 3,07\% está en desacuerdo, 4,69\% totalmente en desacuerdo y el 0,18\% dejaron en blanco. 2) Marketing, el 53,97\% está totalmente de acuerdo, el 30,87\% está de acuerdo, el 7,40\% está indeciso, el 3,25\% está en desacuerdo, 4,33\% totalmente en desacuerdo y el $0,18 \%$ dejaron en blanco. 3) contabilidad, el $60,47 \%$ está totalmente de acuerdo, el $28,52 \%$ está de acuerdo, el 4,51\% está indeciso, el 2,35\% está en desacuerdo, 3,61\% totalmente en desacuerdo y el 0,54\% dejaron en blanco. 4) administración el 61,73\% está totalmente de acuerdo, el $28,34 \%$ está de acuerdo, el 4,87\% está indeciso, el 1,81\% está en desacuerdo, $3,07 \%$ totalmente en desacuerdo y el $0,18 \%$ dejaron en blanco. 5) normativa legal vigente, el $49,28 \%$ está totalmente de acuerdo, el $26,35 \%$ está de acuerdo, el $13,54 \%$ está indeciso, el $5,05 \%$ está en desacuerdo, $5,60 \%$ totalmente en desacuerdo y el $0,18 \%$ dejaron en blanco. 6) otra formación el 1,62\% está totalmente de acuerdo, el 1,26\% está de acuerdo, el 0,18\% está indeciso, el $0,90 \%$ está en desacuerdo, $86,28 \%$ totalmente en desacuerdo y el $9,75 \%$ dejaron en blanco.

Para materializar sus proyectos las mipymes en cuanto a su crecimiento y expansión, consideran a las fuentes de fondeo como un elemento de alto impacto. El $47 \%$ indicaron que la procedencia de los recursos con los que operan son producto de los préstamos de Instituciones Financieras, el $38 \%$ de ahorros propios, el $11 \%$ de préstamo familiar, el $1 \%$ de otras fuentes y el $3 \%$ en blanco. Entre las entidades financieras que han concedido recursos mediante la figura de crédito a los negocios del cantón Guaranda se detallan de acuerdo a la participación: el 36\% Bancos, el 35\% en blanco, el 14\% Instituciones del sector Financiero Popular y Solidario y el $10 \%$ otro tipo de entidad. Aspecto que denota que es muy baja la participación de las Instituciones del sector financiero Popular y Solidario, cuando estas instituciones están destinadas a ser la principal fuente de financiamiento de los negocios.

\subsection{Factores de éxito.}

En inherencia a los factores más determinantes del éxito de las mipymes se encuentra 1) el conocimiento del mercado, al respecto el $52,53 \%$ de los propietarios y/o administradores de los negocios señalaron estar totalmente de acuerdo, el 34,48\% estar de acuerdo, el 6,32\% 
estar indeciso, el 2,89\% estar en desacuerdo, el 3,61\% totalmente en desacuerdo y el $0,18 \%$ dejaron en blanco. 2) capacidad de financiamiento, el 43,86\% está totalmente de acuerdo, el $36,82 \%$ está de acuerdo, el $11,01 \%$ está indeciso, el 1,81\% está en desacuerdo, $6,32 \%$ totalmente en desacuerdo y el $0,18 \%$ dejaron en blanco. 3) conocimiento de estrategias de publicidad y propaganda, el 43,32\% está totalmente de acuerdo, el 33,21\% está de acuerdo, el $12,09 \%$ está indeciso, el 5,78\% está en desacuerdo, 5,42\% totalmente en desacuerdo y el $0,18 \%$ dejaron en blanco. 4) producto o servicio adecuado, el 55,96\% está totalmente de acuerdo, el 27,80\% está de acuerdo, el 5,96\% está indeciso, el 3,97\% está en desacuerdo, $6,14 \%$ totalmente en desacuerdo y el $0,18 \%$ dejaron en blanco. 5) conocimiento de estrategias de comercialización, el 48,56\% está totalmente de acuerdo, el 30,32\% está de acuerdo, el $7,94 \%$ está indeciso, el 4,33\% está en desacuerdo, 8,66\% totalmente en desacuerdo y el $0,18 \%$ dejaron en blanco. 6) capacidad para afrontar la competencia, el 50,90\% está totalmente de acuerdo, el 29,96\% está de acuerdo, el 10,65\% está indeciso, el 3,07\% está en desacuerdo, $4,69 \%$ totalmente en desacuerdo y el $0,72 \%$ dejaron en blanco. 7) conocimiento de los fundamentos de la gestión de un negocio, el 47,83\% está totalmente de acuerdo, el $31,95 \%$ está de acuerdo, el 10,83\% está indeciso, el 3,43\% está en desacuerdo, 5,60\% totalmente en desacuerdo y el 0,36\% dejaron en blanco. 8) conocimiento sobre Planificación, el 50,36\% está totalmente de acuerdo, el 29,60\% está de acuerdo, el 10,11\% está indeciso, el 2,35\% está en desacuerdo, $7,40 \%$ totalmente en desacuerdo y el $0,18 \%$ dejaron en blanco. 9) capacidad de adaptación al entorno económico, político y social, el 48,19\% está totalmente de acuerdo, el 32,13\% está de acuerdo, el 10,65\% está indeciso, el 3,07\% está en desacuerdo, $5,78 \%$ totalmente en desacuerdo y el $0,18 \%$ dejaron en blanco. 10) personal altamente capacitado, el 49,46\% está totalmente de acuerdo, el 28,16\% está de acuerdo, el $9,93 \%$ está indeciso, el 5,96\% está en desacuerdo, 6,32\% totalmente en desacuerdo y el $0,18 \%$ dejaron en blanco. 11) impuestos Municipales y Tributarios bajos, el 46,03\% está totalmente de acuerdo, el 28,70\% está de acuerdo, el 13\% está indeciso, el 4,69\% está en desacuerdo, $7,40 \%$ totalmente en desacuerdo y el $0,18 \%$ dejaron en blanco. 12) conocimiento de leyes conexas relacionadas con los emprendimientos, el $46,57 \%$ está totalmente de acuerdo, el $26,71 \%$ está de acuerdo, el 13,54\% está indeciso, el 6,50\% está en desacuerdo, $6,50 \%$ totalmente en desacuerdo y el $0,18 \%$ dejaron en blanco. 13) otros factores, el $1,26 \%$ está totalmente de acuerdo y está de acuerdo, el 0,18\% está indeciso, el 95,49\% totalmente en desacuerdo y el $1,81 \%$ dejaron en blanco. 


\subsection{Expansión del negocio.}

Finalmente señalaron que de acuerdo a su experiencia expandiría su negocio en un $82 \%$ y el $15 \%$ señalaron que no y por otro lado el $3 \%$ dejaron en blanco.

Tabla 2. Entrevistas aplicadas a propietarios de mipymes en el Cantón Guaranda.

\begin{tabular}{ll}
\hline Preguntas & Respuestas \\
\hline De acuerdo a su criterio ¿Cuáles & Visión \\
deberían ser las características que debe & Liderazgo \\
poseer un emprendedor? & Iniciativa \\
& Responsabilidad \\
& Habilidades de comunicación \\
¿Cree Usted que los emprendimientos & Los emprendimientos no son producto de \\
de Guaranda son producto de un estudio & estudios de mercado; pues para establecer un \\
de mercado? & negocio no consideran los elementos como: \\
& producto, precio, oferta, demanda, canales de \\
& comercialización, mercado, entre otros. Es por tal \\
& razón que los emprendimientos son puestos en \\
& marcha bajo conocimientos tradicionales \\
& (empíricos).
\end{tabular}

De acuerdo a su criterio ¿Quiénes son La mayor parte de emprendimientos son iniciados más emprendedores los hombres o las y gestionados por mujeres.

mujeres?

¿Cuál cree usted, que son las principales Las principales razones son la falta de formación razones por las cuales los empresarial y el desconocimiento de aspectos emprendedores cierran sus negocios? como: contabilidad, administración, etc., así como también la falta de asesoramiento anterior a iniciar el negocio.

¿Cuál cree usted que son los principales

- Estudio de mercado

factores de éxito de las Mipymes?

- Capacidad de adaptación al entorno económico, político y social.

- Cocimiento sobre marketing, administración, contabilidad, etc. 
- Capacidad de financiamiento

- Personal altamente capacitado

De acuerdo a su criterio ¿Cuáles Buscar fuentes de financiamiento en la que el deberían ser las acciones que deberían margen financiero sea favorable para la empresa. seguir los emprendedores para mantener operativo sus Mipymes?

¿Qué error considera usted, que debe El sobrendeudamiento por la utilización de los evitar cometer un emprendedor? recursos otorgados como créditos en actividades no afines a su destino.

¿Qué habilidades cree usted, que debe Habilidades de negociación, de comunicación y entrenar constantemente un liderazgo. emprendedor?

¿Cuál cree usted, que debe ser el papel Establecimiento de políticas económicas que del Gobierno Nacional con respecto a los coadyuven a su supervivencia en el mercado. Ej. empresarios? Reducción de impuestos.

¿Cuál cree usted, que es el elemento En nuestra ciudad existen grandes recursos por diferenciador de las Mipymes de la explotar, pero la gente opta por las costumbres y ciudad de Guaranda y otras ciudades? tradiciones de otras ciudades.

¿Considera usted, que existe una Existe una estrecha relación entre la formación relación beneficiosa entre la formación profesional y el éxito competitivo de una mipyme profesional del gerente y el éxito puesto que ayuda a mejorar sus resultados. competitivo de una Mipymes?

¿Cree usted, que el emprendedor de un El inicio de un negocio comprende asumir riesgos negocio tiene sus riesgos? ¿Cuáles son? inherentes como los riesgos de mercado, liquidez, de crédito, de mercado, estratégico, etc.

$\mathrm{Si}$ el Estado mediante las instancias La asistencia creditico por parte de las IFI"S en pertinentes brindarían mayor número de especial las IFI'S del sector Financiero Popular y facilidades de acceder a un crédito se Solidario, es un factor de éxito. rehabilitarían negocios pasivos?

Fuente: elaboración propia. 


\section{DISCUSIÓN}

Un factor de éxito de las mipymes es que la administración de éstas sea realizada por emprendedores que sean visionarios, líderes, responsables, etc., y con la formación empresarial apropiada; así mismo que todo negocio está sujeto a riesgos y que estas organizaciones son gestionadas mayoritariamente por mujeres.

Uno de los principales errores cometidos por los emprendedores a la hora de iniciar sus negocios es que lo hacen sin un estudio de mercado. Así también se pudo determinar que entre las principales causas para que los emprendimientos cierren son la falta de formación empresarial y el desconocimiento de aspectos como: contabilidad, administración, etc., así como también la falta de asesoramiento anterior a iniciar el negocio y la falta de financiamiento por parte de las IFIS.

\section{CONCLUSIONES}

Por la importancia a las Mipymes y su problemática para sobrevivir y competir en un mercado globalizado cada vez más exigente, se pone de manifiesto la necesidad de analizar los factores de éxito que determinan su competitividad, tomando en consideración que las mipymes en horizontes de Latinoamérica y a nivel mundial representan un aporte importante dentro de la estructura económica de los países, puesto que representa una oportunidad y un aliciente principal en la generación de riqueza, mediante la producción y el establecimiento de múltiples fuentes de empleo en los sectores como el comercio, industrial y servicios, como producto de la investigación se pudo concluir:

El quehacer empresarial de las mipymes está encasillado en satisfacer las necesidades variadas de quien consume o hace uso del bien o servicio que oferta en el mercado regional, nacional o internacional, mismas que son administradas en gran medida por propietarios y/o administradores de género femenino que ostentan una edad que bordean los rangos de 20 a 40 años. Asimismo, el grado de instrucción que predomina en los encuestados es la primaria secundaria y muy poca participación de la formación académica de alto nivel.

Los recursos utilizados en el quehacer empresarial de la mipyme proceden en mayor proporción de préstamos de instituciones financieras, en especial de Bancos seguido por los ahorros propios. Al hacer hincapié de que la principal fuente de financiamiento son los Bancos, esto no significa que sean conocedores de las exigencias de estas instituciones para el 
otorgamiento de créditos en cuanto a requisitos y garantías o que conozcan de manera acertada las instituciones que ofrecen los recursos para que sean invertidas en actividades productivas.

Las mipymes en el Ecuador desarrollan diversas actividades económicas como la comercial industrial y de servicios, sin embargo, la actividad económica que predomina en este sector del cantón Guaranda es la de comercio. Por otro lado, el tamaño de las empresas que prepondera, es micro y pequeñas y es muy escaza la participación de estas organizaciones de tamaño mediana.

Realizada la investigación se pudo identificar los principales factores que influyen y promueven el éxito de las mipymes del cantón Guaranda y las ayuden a su supervivencia en el mercado, por el criterio de los encuestados que están totalmente de acuerdo y de acuerdo con estos en promedio del $74 \%$, entre las cuales se encuentran: 1 ) conocimiento del mercado. 2) Capacidad de financiamiento. 3) Conocimiento de estrategias de publicidad y propaganda.4) Producto o servicio adecuado.5) Conocimiento de estrategias de comercialización.6) Capacidad para afrontar la competencia.7) Conocimiento de los fundamentos de la gestión de un negocio.8) Conocimiento sobre Planificación.9) Capacidad de adaptación al entorno económico, político y social.10) Personal altamente capacitado.11) Impuestos Municipales y Tributarios bajos.12) Conocimiento de leyes conexas relacionadas con los emprendimientos.

Al realizar la compilación de ideas realizadas a los entrevistados de los negocios se puedo concluir que todo emprendedor debe reunir las capacidades idóneas, habilidades de negociación, comunicación y liderazgo para gestionar una empresa y ser perseverante en su decisión, así como asumir riesgos por lo que las mipymes creadas en la ciudad de Guaranda se han puesto en marcha bajo conocimiento tradicionales mas no por un estudio de mercado, de lo que se pudo verificar en este sector el género femenino son más emprendedoras $y$, en su mayor parte los negocios son administradas y gerenciadas por mujeres; pero lamentablemente la falta de financiamiento merma el crecimiento empresarial, por lo que sugieren que el gobierno debería tomar acciones para fomentar políticas de financiamiento que coadyuven a su supervivencia de las mipymes en el mercado. 


\section{REFERENCIAS BIBLIOGRÁFICAS}

Ahmedova, S. (2015). Factors for Increasing the Competitiveness of Small and MediumSized Enterprises .(SMEs) in Bulgaria. Procedia - Social and Behavioral .Sciences , 195.1104-1112. https://doi.org/10.1016/j.sbspro.2015.06.155 .

Carroll, A. B. (1991). The pyramid of corporate social responsibility: Toward the moral management of organizational stakeholders. Business Horizons, 34(4), 39-48. DOI:10.1016/0007-6813(91)90005-g.

Castro, I. y Rufino, J. (2015). Creación de empresas para emprendedores. Madrid: Pirámide.

Cravo, A.; Bettina, B. \& Gourlay, A. (2014). Regional Growth and SMEs in Brazil: A Spatial Panel Approach. Regional Studies.49(12), 1995-2016. https://doi.org/10.1080/00343404.2014.890704.

Estrada, P.; García, D \& Sánchez,V. (2009). Resumen de resultados segunda encuesta PYME, proyecto: Planeación estratégica y herramientas de gestión. Universidad de Hidalgo.

Gill, A.; Nahum, B. \& Vivek, N. (2011). Barriers to small business creations in Canada. Journal of Small.Business and Enterprise Development.19(4), 656-668. https://doi.org/10.1108/14626001211277451.

Gutiérrez, R.J. (2009). Factores que intervienen en el éxito empresarial, El Cid Editor | apuntes, . ProQuest Ebook Central, http://ebookcentral.proquest.com/lib/uebecsp/detail.action?doc/D=3179883.

Hernández, R. (2007). Las MIPYMES en Latinoamérica, B - EUMED, ProQuest Ebook Central,http://ebookcentral.proquest.com/lib/uebecsp/detail.action?doc/D=3200430.

INEC. (2010). http://www.ecuadorencifras.gob.ec/documentos/webinec/EMPLEO/Panorama\%20Laboral/20100922_LanzamientoPanoramaLaboral.pdf.

Longenecker, J.-W. P. (2012). Administración de pequeñas empresas Lanzamiento y crecimiento de iniciativas de emprendimiento. Mexico: Javier Reyes martinez.

López, V.H. (2009). Factores del éxito empresarial en San Juan de Pasto, El Cid Editor | apuntes. ProQuest Ebook Central, http://ebookcentral.proquest.com/lib/uebecsp/detail.action?doc/D=3182811.

Lynch, R. (2003). Corporate Strategy. Prentice Hall, London.

Martín, P. A. (2013). Universidad Nacional de Colombia Facultad de Ciencias y Administración. Obtenido de Tesis de investigación: http://bdigital.unal.edu.co/9637/1/7709552.2013.pdf.

Nalband, \& Kelabi. (2014). Redesigning Carroll's CSR Pyramid Model. Journal of Advanced Management Science, 2(3), 236-239. DOI: 10.12720/joams.2.3.236-239. 
Pulido, B. (2010). Teoría de los recursos y capacidades: el foco es-tratégico centrado en el interior de la organización. Sotavento M.B.Z, 54-61. doi:ISSN 0123-373.

Ramírez, H. y Venegas, B. (2008). Gestión de costos en las PYMES: problemática y alternativas de solución, Universidad Libre, ProQuest Ebook Central, http://ebookcentral.proquest.com/lib/uebecsp/detail.action?doc/D=3179080.

Rodríguez, J. (2006). Dirección Moderna de Organziaciones. méxico D.F.: International Thomson Ediores, S.A.

Scali, J. y Tapia, G. (2012). Tablero de Comando en las PyMEs (Primera ed.). México D. F., México: Alfaomega Grupo Editor.

SRI. (2012). Servicio de Rentas Internas. Recuperado el 9 de Marzo de 2015, de http://www.sri.gob.ec/de/32.

Vásquez, O. (2002). La idónea implementación estra-tégica es condición necesaria para aspirar al éxito de la empresa. Estudios Gerenciales, 43-46.doi:0123-5923.

Vega, R. et al. (2011). PYMES: reflexiones para la pequeña y mediana empresa en Colombia, Editorial Politécnico Grancolombiano, ProQuest Ebook Central, http://ebookcentral.proquest.com/lib/uebecsp/detail.action?doc/D=3216886. 